\author{
Muhammed Fatih Kilicaslan $^{\text {a*, Saad Ibrahim Elburni }}{ }^{\mathrm{b}}$, Bekir Akgul ${ }^{\mathrm{c}}$ \\ ${ }^{a}$ Department of Fundamental Sciences and Engineering, Sivas University of Science and \\ Technology, 58000, Sivas Turkey \\ ${ }^{b}$ Department of Materials Science and Engineering, Kastamonu University, 37000, \\ Kastamonu, Turkey \\ ${ }^{c}$ Department of Aeronautical Engineering, Sivas University of Science and Technology, \\ 58000, Sivas, Turkey \\ *fatihkilicaslan@sivas.edu.tr
}

\title{
THE EFFECTS OF Nb ADDITION ON THE MICROSTRUCTURE AND MECHANICAL PROPERTIES OF MELT SPUN Al-7075 ALLOY
}

\begin{abstract}
The mechanical properties of the Al-7075 material, which is used in important areas such as automotive, aviation and defense industry, are still being studied by researchers. In this study, the effects of different proportions of $\mathrm{Nb}$ additives on the microstructure and mechanical properties of the rapidly solidified Al-7075 alloy was investigated. Rapid solidification processes were carried out with a single roller melt spinner at a disk surface speed of $25 \mathrm{~m} / \mathrm{s}$. Microstructure characterization was performed by using a scanning electron microscopy (SEM) and X-ray diffraction. According to the results, the $\mathrm{Nb}$ additive significantly increased the micro hardness of the Al-7075 alloy. The microhardness of the sample added with $0.5 \%$ by weight of $\mathrm{Nb}$ is $0.9 \mathrm{GPa}$. This value is 3 times higher than the sample without $\mathrm{Nb}$ added. The $\mathrm{Nb}$ contribution has led to modification of the dimensions and shapes of both $\alpha-\mathrm{Al}$ and intermetallic phases. $\mathrm{Nb}$ addition reduced the average grain size from $9.1 \mu \mathrm{m}$ to $2.46 \mu \mathrm{m}$.
\end{abstract}

Keywords: Metals and alloys; microstructure; metallurgy

\section{INTRODUCTION}

Aluminum and its alloys, especially Al-7075 series ones, are frequently used in aviation and automotive industries due to their low density, high strength, ductility and fatigue resistance [1-4]. Although the Al-7075 alloy has excellent properties, researchers are still working to improve some of the properties of this material $[2,5,6]$. In order to further improve the mechanical properties of aluminum alloys, researchers make microstructure modifications by means of various additive elements such as $\mathrm{Co}, \mathrm{Ni}, \mathrm{V}, \mathrm{Sc}, \mathrm{Ti}, \mathrm{B}$ and / or use new generation production techniques [7-9]. Methods such as precipitation hardening [10-12], deformation hardening $[13,14]$, semi-solid casting $[15,16]$ and/or various rapid solidification[2,5,17-19] are applied to aluminum alloys whose strength cannot be increased by quenching. Many alloying elements are added to the aluminum alloy to refine the grain size by operating the heterogeneous nucleation mechanism. Nucleation centers are increased 
by the formation of high melting intermetallic phases such as $\mathrm{MgZn}_{2}, \mathrm{Al}_{3} \mathrm{Sc}, \mathrm{Al}_{3} \mathrm{Nb}$, $\mathrm{Al}_{2} \mathrm{CuMg}, \mathrm{Al}_{7} \mathrm{Cu}_{2} \mathrm{Fe}, \mathrm{MgZn}_{2}, \mathrm{Al}_{6} \mathrm{AgMg}_{4}$. In this way, the grain size gets thinner as the number of grains in the structure increases $[9,12,14,20]$. Additionally, melt spinning, a kind of rapid solidification techniques, is a new generation production method that allows the production of superior aluminum alloys. The melt spinning method stands out because it produces high cooling rates such as $10^{7} \mathrm{~K} / \mathrm{s}$ and is suitable for mass production $[6,9,21,22]$. Rapid solidification process in aluminum alloys provides benefits such as reduction of segregation, grain size refinement, suppression or elimination of coarse segregation phases, modification of secondary phases in terms of size and shape, increase of chemical homogeneity, minimization of time or temperature in aging processes [2,5,21,23,24]. Unlike traditional production methods, the grain size of the materials produced by rapid solidification is finer. As is known, the mechanical properties of fine-grained structures such as hardness, tensile strength, and fatigue strength are better than coarse-grained structures $[2,5,6,9,22,25,26]$. In traditional production methods, an alloying element such as Ti-B can be added as a grain refiner [27]. It is also known that element $\mathrm{Nb}$ is added to various alloys as a grain refiner and strength enhancer [28,29]. In Wang's study, it is stated that $\mathrm{Nb}$ and $\mathrm{Al}$ elements form $\mathrm{Al}_{3} \mathrm{Nb}$ intermetallic compound and this phase is located approximately in the center of the grains and plays a role in initiating nucleation [28]. The $\mathrm{Nb}$ element reduces structural undercooling by operating the heterogeneous nucleation mechanism to form codispersed fine particles in the structure [26,29]. Nowak et al. emphasized in their study that $\mathrm{Nb}-\mathrm{B}$ addition is more effective than commercial Ti-B addition in grain refinement [29]. In this way, a microstructure with homogeneous distribution and minimum segregation is obtained within the structure. The melt spinning method also minimizes the chemical composition segregation seen in conventional methods [26]. According to the study conducted by Liu et al. in 2021, grain size and micro segregation decrease with increasing cooling rate [26]. Unfortunately, it is known that there are micro-chemical composition differences between the fast-solidifying region and the slow-solidifying region in traditional production methods. Therefore, in the melt spinning method, since the whole structure solidifies rapidly, there is no difference in composition distribution. However, to our best knowledge, there is not enough information in the open literature on the effects of $\mathrm{Nb}$ doping on the microstructure and mechanical properties of rapidly solidified Al-7075 alloys. In addition, T6 heat treatment is applied to increase the strength of Al-7075 alloys. However, as this increases the grain size, it can increase the hardness up to a certain point [30]. For this reason, in the presented study, effect of $\mathrm{Nb}$ contribution on microstructure and mechanical properties of Al-7075 alloy produced by melt spinning method is examined. In this way, the effect of $\mathrm{Nb}$ addition to Al-7075 alloy known as aviation material and melt spinning method on microstructure and mechanical properties has been demonstrated. Unlike traditional production methods, it has been shown that the hardness can be carried to higher points by forming a very fine grain structure with the melt spinning method. As a matter of fact, the hardness has increased approximately three times without heat treatment.

\section{EXPERIMENTAL}

A commercial purity $\mathrm{Al}-7075$ and $\mathrm{Nb}$ alloys were used to prepare $\mathrm{Al}-7075-\mathrm{XNb}$ alloys $(\mathrm{X}=\mathrm{wt} \% 0.2$ and 0.5$)$ with nominal composition. Al10Nb master alloy with a size of 0.5-3 $\mathrm{mm}$ is used as $\mathrm{Nb}$ raw material. Samples with $500 \mathrm{~g}$ of composition were melted twice for homogeneous mixture in high frequency induction furnace. All sample mixtures were taken 
up to $750^{\circ} \mathrm{C}$ and kept for 15 minutes and then poured into an ingot mold at $700{ }^{\circ} \mathrm{C}$. In addition, the selection of the rotation speed of the copper disc is one of the important parameters affecting the cooling rate and ribbon thickness. According to Qing et al., a cooling rate of $2 \times 10^{7} \mathrm{~K} / \mathrm{s}$ was obtained at $30 \mathrm{~m} / \mathrm{s}$ disk speed and mechanical properties such as hardness increased with the refining of the grain size [22]. Therefore, the melt spinning processes were performed using a copper wheel with $25 \mathrm{~m} / \mathrm{s}$ disc velocity with pressurized argon of 400 mbar. As can be seen in Figure 1, cylindrical samples weighing approximately $500 \mathrm{~g}$ and $10 \mathrm{~cm}$ in length were melted in the high-frequency induction furnace again in the melt spinning process and blown through a nozzle at a distance of $1 \mathrm{~mm}$ onto the copper disc with an argon pressure of 400 mbar. As a result, ribbons of approximately $10 \mathrm{~mm}$ width and $30 \mu \mathrm{m}$ thickness were obtained.
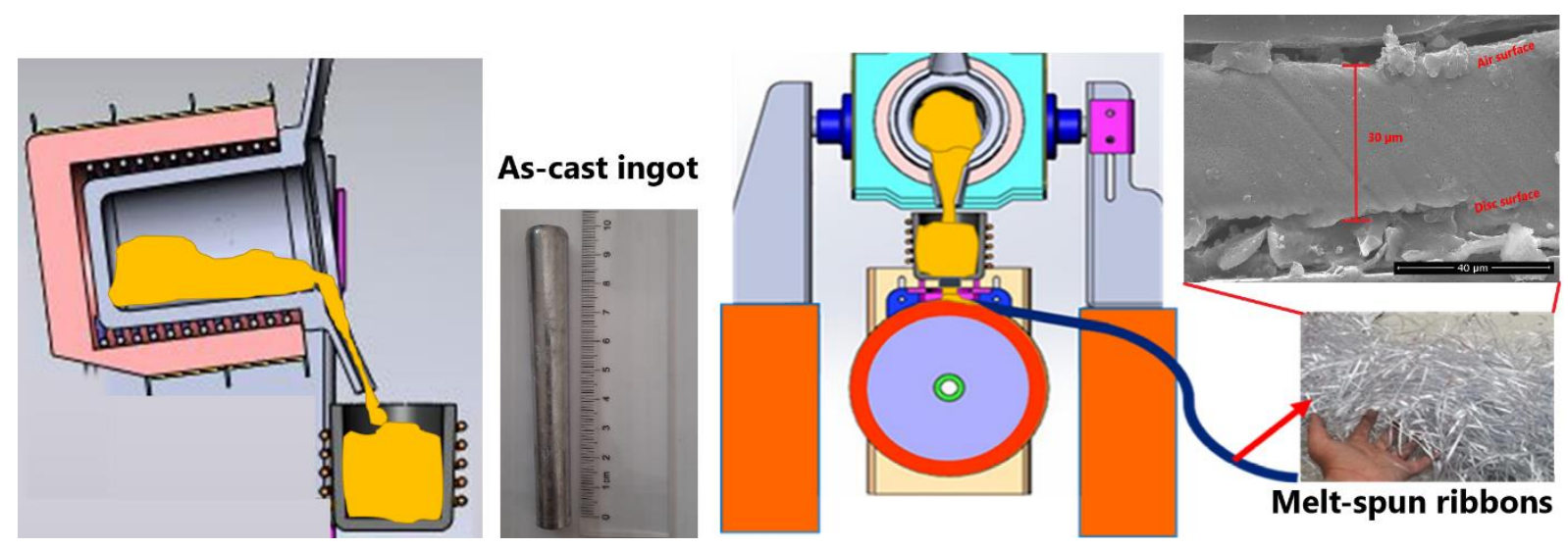

Fig. 1. Melt-spinning process

While melt-spun ribbons were denoted as AA00 ( $\mathrm{Nb}$ free alloy), AA02 (0.2 Nb added) and AA05 (0.5 Niobium added), as-cast alloys were denoted as CA00 ( $\mathrm{Nb}$ free alloy), CA02 (0.2 Nb added) and CA05 (0.5 Nb added). All of the specimens fabricated are given in Table 1. The cross-sections of ribbons were selected for the indentation and scanning electron microscopy measurements. The microstructure and phase identification of the samples were investigated by FEI Quanta FEG 250 scanning electron microscopy (SEM), SEM-Energy dispersive spectrometer (EDS) and a Bruker D8 Advance X-ray diffractometer. For microhardness hardness measurements, a microhardness tester with a Vickers tip (HMVG21D) was used. All tests were performed under the same operating conditions. For all samples, the maximum load was $0.55 \mathrm{~N}$.

Table 1. Chemical composition of melt spun Al-7075 alloys (wt. \%)

\begin{tabular}{lcccccccccccc}
\hline Sample & $\mathrm{Si}$ & $\mathrm{Cu}$ & $\mathrm{Mn}$ & $\mathrm{Mg}$ & $\mathrm{Cr}$ & $\mathrm{Zn}$ & $\mathrm{Ti}$ & $\mathrm{Nb}$ & $\mathrm{Fe}$ & $\mathrm{Pb}$ & $\mathrm{Sn}$ & $\mathrm{Al}$ \\
\hline $\begin{array}{l}\text { AA00/ } \\
\text { CA00 }\end{array}$ & 0.727 & 1.64 & 0.053 & 2.48 & 0.263 & 6.52 & 0.095 & - & 0.115 & 0.009 & 0.008 & bal. \\
AA02/ & 0.727 & 1.64 & 0.053 & 2.48 & 0.263 & 6.52 & 0.095 & 0.2 & 0.115 & 0.009 & 0.008 & bal. \\
CA02 & & & & & & & & & & & & \\
$\begin{array}{l}\text { AA05/ } \\
\text { CA05 }\end{array}$ & 0.727 & 1.64 & 0.053 & 2.48 & 0.263 & 6.52 & 0.095 & 0.5 & 0.115 & 0.009 & 0.008 & bal. \\
\hline
\end{tabular}




\section{RESULTS AND DISCUSSION}

Figure 2 shows how the microstructure is evolved with the addition of $\mathrm{Nb}$ in as-cast (Figure 2 ( $a, b$ and c). Accordingly, in the sample without additives (AA00) seen Figure 2 (a), the $\alpha$-Al grains vary between about $7 \mu \mathrm{m}$ and $17 \mu \mathrm{m}$ and their average size is $9.1 \mu \mathrm{m}$. In Figure 2 (b), that is, in the sample with $0.2 \mathrm{Nb}$ doping (AA02), the sizes of $\alpha$-Al grains vary between $1.9 \mu \mathrm{m}$ and $7.7 \mu \mathrm{m}$. Here, the average grain size of $\alpha-\mathrm{Al}$ is around $4.5 \mu \mathrm{m}$. As for the sample AA05 with $0.5 \mathrm{Nb}$ (Figure 2 (c)), the particle size of the $\alpha$-Al phase varies between 1 $\mu \mathrm{m}$ and $5.6 \mu \mathrm{m}$ and the average particle size of them is approximately $2.46 \mu \mathrm{m}$. Hence, the $\mathrm{Nb}$ contribution to the Al-7075 alloy gradually caused a reduction in the particle sizes of the $\alpha$-Al phases. In addition, with the $\mathrm{Nb}$ additive, both the distribution of the $\alpha$-Al phases became more homogeneous and their shapes transformed from an irregular structure (Figure 2 (a)) to a coaxial structure (Figure 2 (c)). Two factors can be mentioned that make the grains fine and homogeneous. First; As Wang stated in his work, the element $\mathrm{Nb}$ increased the heterogeneous nucleation in aluminum and increased the number of grains [28]. In this way, structural undercooling has decreased. According to Nowak, more homogeneous and finergrained structures are formed due to the addition of $\mathrm{Nb}$ [29]. Therefore, it is seen that the data we obtained in our study are compatible with the studies of Wang and Nowak [28,29]. The second factor is that the grains formed during cooling due to the rapid cooling caused by the melt spinning cannot find the opportunity to grow. In this way, it is ensured that almost nanosized particles are formed. In the study carried out by Meng in 2020, a grain size of approximately 2-4 $\mu \mathrm{m}$ was obtained [25]. In our study, close grain sizes were obtained in the sample with $0.5 \% \mathrm{Nb}$ added. In this study, the lowest average particle size of $2.46 \mu \mathrm{m}$ was obtained with a cooling speed of $25 \mathrm{~m} / \mathrm{s}$. However, Lin et al. Obtained an average particle size of $1.6 \mu \mathrm{m}$ at a cooling rate of $40 \mathrm{~m} / \mathrm{s}$ [2]. This shows that as the cooling rate increases, the grain size decreases.

Figure 2 (d) shows XRD patterns taken from the samples. According to XRD analysis, only well-defined Al crystal peaks are seen in all three samples, and the clear peak of any intermetallic is not visible. Possible reasons for not finding any intermetallics in this study may be that intermetallics have very small dimensions due to rapid solidification and / or their ratio within the microstructure is too low. Because XRD is insufficient in detecting phases less than a certain ratio within the microstructure [31]. On the other hand, in Figure 2 (d), within the small frame indicated by an arrow, the $2 \theta$ angles at which Al (111) peaks are formed are seen. As can be seen from the figure, with the $\mathrm{Nb}$ doping, Al peaks shift to the right, that is, they occur at larger $2 \theta$ values. In the literature, this situation is associated with the dissolution of some of the additive element in Al matrix. On the other hand, in ref. [32], it is stated that in the rapidly solidified $\mathrm{Al}-\mathrm{Si}$ alloys alloy, transition metals can be dissolved in the Al matrix. Thus, we think that in the samples with the $\mathrm{Nb}$ doped, some $\mathrm{Nb}$ dissolved in the Al matrix and formed a solute solution. In addition, although the $\mathrm{Nb}$ peaks are very uncertain, Wang et al. Stated in 2014 that there is an $\mathrm{Al}_{3} \mathrm{Nb}$ phase in the structure [28]. $\mathrm{Nb}$ peaks in Wang's study are slightly more pronounced than ours. However, in Wang's work, there is no alloying element other than $\mathrm{Nb}$ in Al. Therefore, it is possible to see and distinguish $\mathrm{Nb}$ peaks. Considering that there are more than one alloying element and phase in our study, it can be understood that $\mathrm{Nb}$ peaks are uncertain. However, it is understood from the SEM and EDS results shown in Figure 3 that the $\mathrm{Nb}$ element is mixed into the structure. As a result of EDS number 1, which is thought to be a nano-sized intermetallic phase, the $\mathrm{Nb}$ ratio has increased to $5.6 \%$. This result shows that there may be $\mathrm{Al}_{3} \mathrm{Nb}$ intermetallic phase emphasized by Wang in microstructure [28]. 

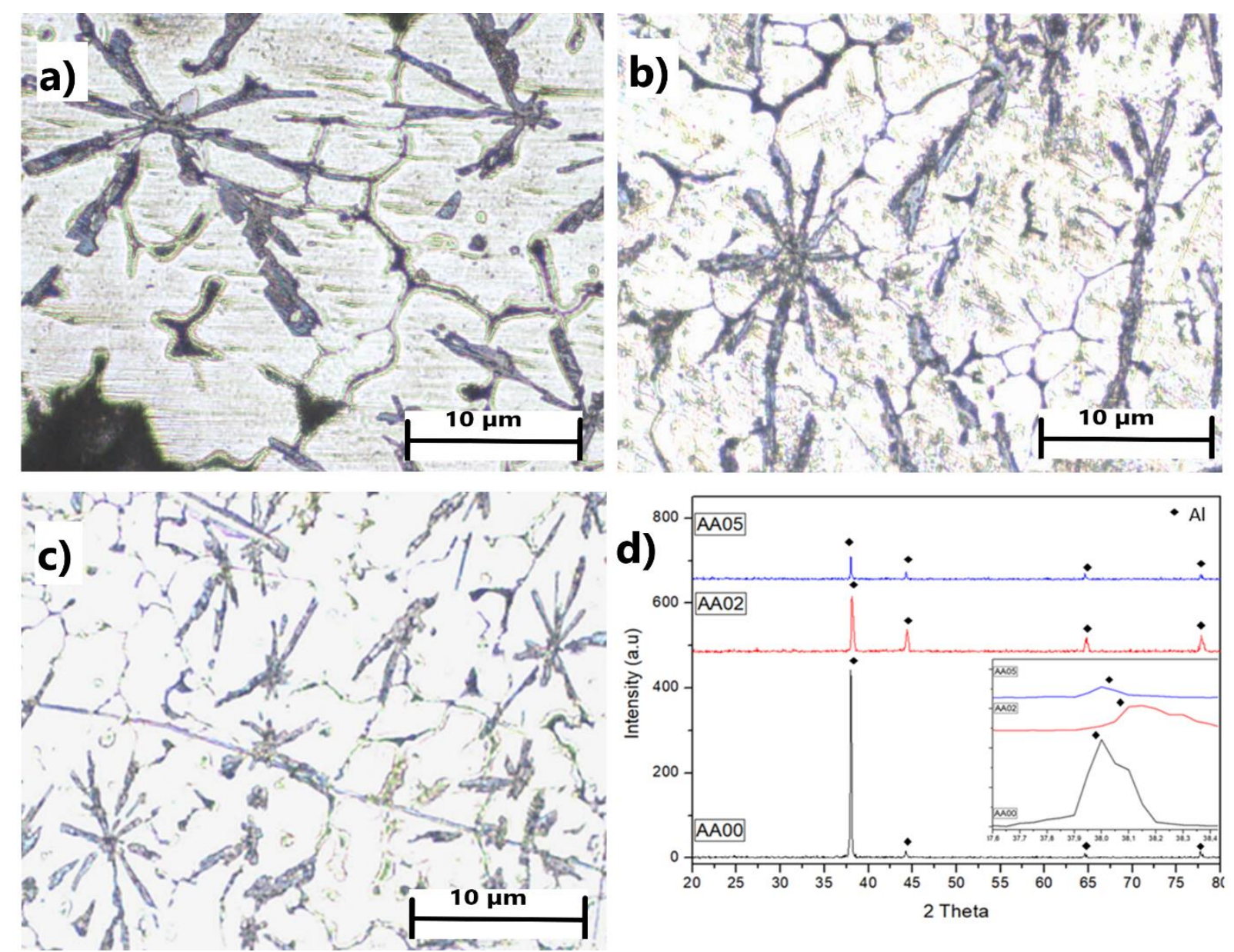

Fig. 2. Optical micrographs as-cast and XRD pattern taken form melt spun Al7075 alloys showing changes in microstructures with addition of $\mathrm{Nb}$; (a) without $\mathrm{Nb}$; (b) with 0.2 pct. $\mathrm{Nb}$; (c) with $0.5 \mathrm{pct}$. Nb; (d) XRD pattern of samples $A A 00, A A 02$, and $A A 05$
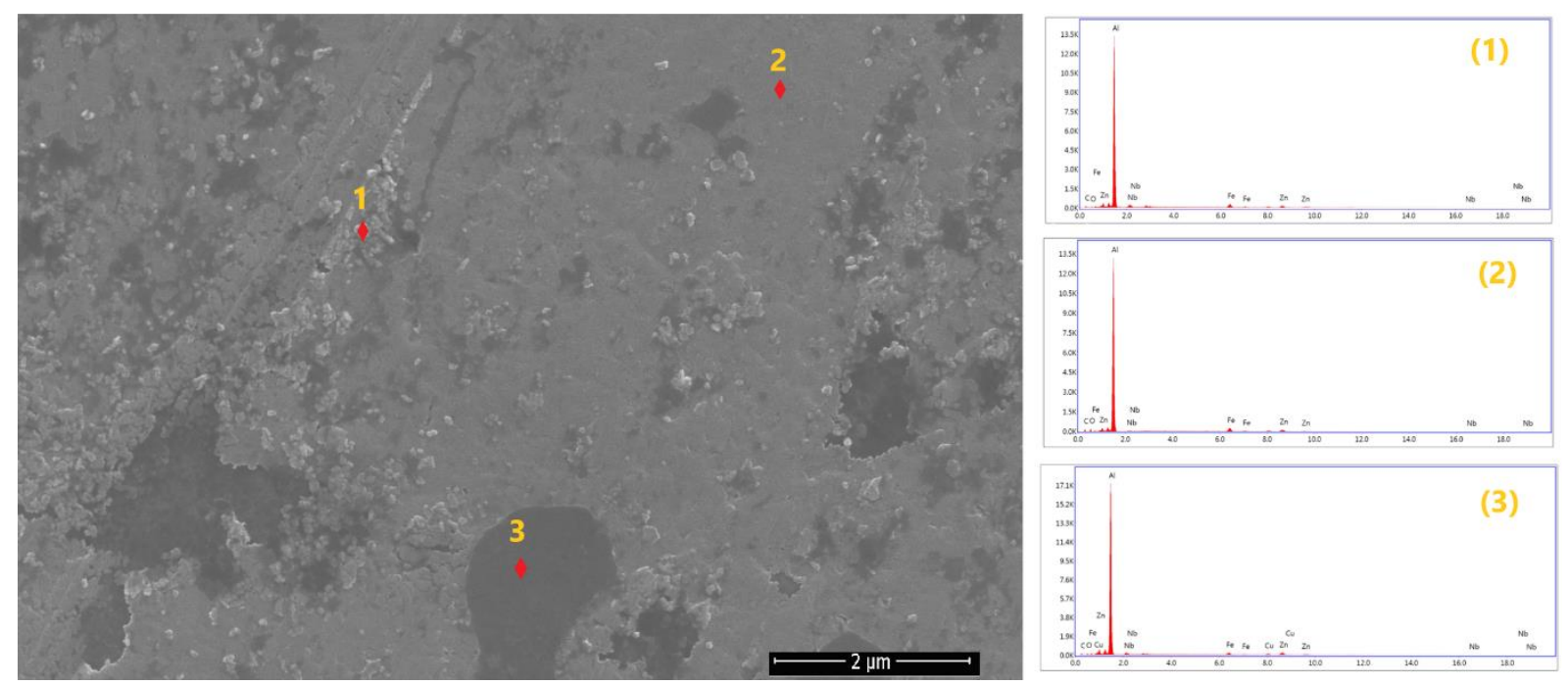

Fig. 3. SEM-EDS analyses from melt-spun AA02 alloy 
The SEM micrographs given in Figure 4 shows how the microstructure of the Al-7075 alloy is evolved with the $\mathrm{Nb}$ addition. In Figure 4 (a), sharp angular particle-like shaped secondary phase grains are observed in the microstructure of the $\mathrm{Nb}$ free sample (AA00). The sizes of these secondary phase particles vary between $0.5 \mu \mathrm{m}$ and $3 \mu \mathrm{m}$, and the average particle size of these secondary phases is around $1.6 \mu \mathrm{m}$. In Figure $4(\mathrm{~b})$, with the $0.2 \mathrm{Nb}$ (sample AA02), the shapes of the secondary phases embedded in the Al matrix are transformed into both particle-like and rectangular block-like structures. In the AA02 sample, the dimensions of the secondary phases varied between $0.2 \mu \mathrm{m}$ and $2.2 \mu \mathrm{m}$, and the average dimensions decreased by $1 \mu \mathrm{m}$ compared to the $\mathrm{Nb}$ sample. When the $\mathrm{Nb}$ contribution is increased to $0.5 \%$ (Figure 4 (c)), the coaxial rounded / spherical shaped secondary phase particles embedded in the Al matrix draw attention in the microstructure of the AA05 sample. The sizes of the rounded / spherical shaped secondary phases vary between $0.3 \mu \mathrm{m}$ and 1.7 $\mu \mathrm{m}$ and the average particle size is around $1 \mu \mathrm{m}$. The secondary phase turns into spherical by adding $0.5 \% \mathrm{Nb}$. Liu stated that by adding $\mathrm{Ce}$ at the same rate as we do, the secondary phases become spherical [22]. Therefore, it can be said that $\mathrm{Nb}$ and Ce elements operate the same heterogeneous nucleation mechanism. Liu showed in his study in 2018 that the cooling rate also affected the formation of spherical secondary phases. According to Liu, after $30 \mathrm{~m} / \mathrm{s}$ cooling rate, it turns into a spherical excess fibrous structure [22].
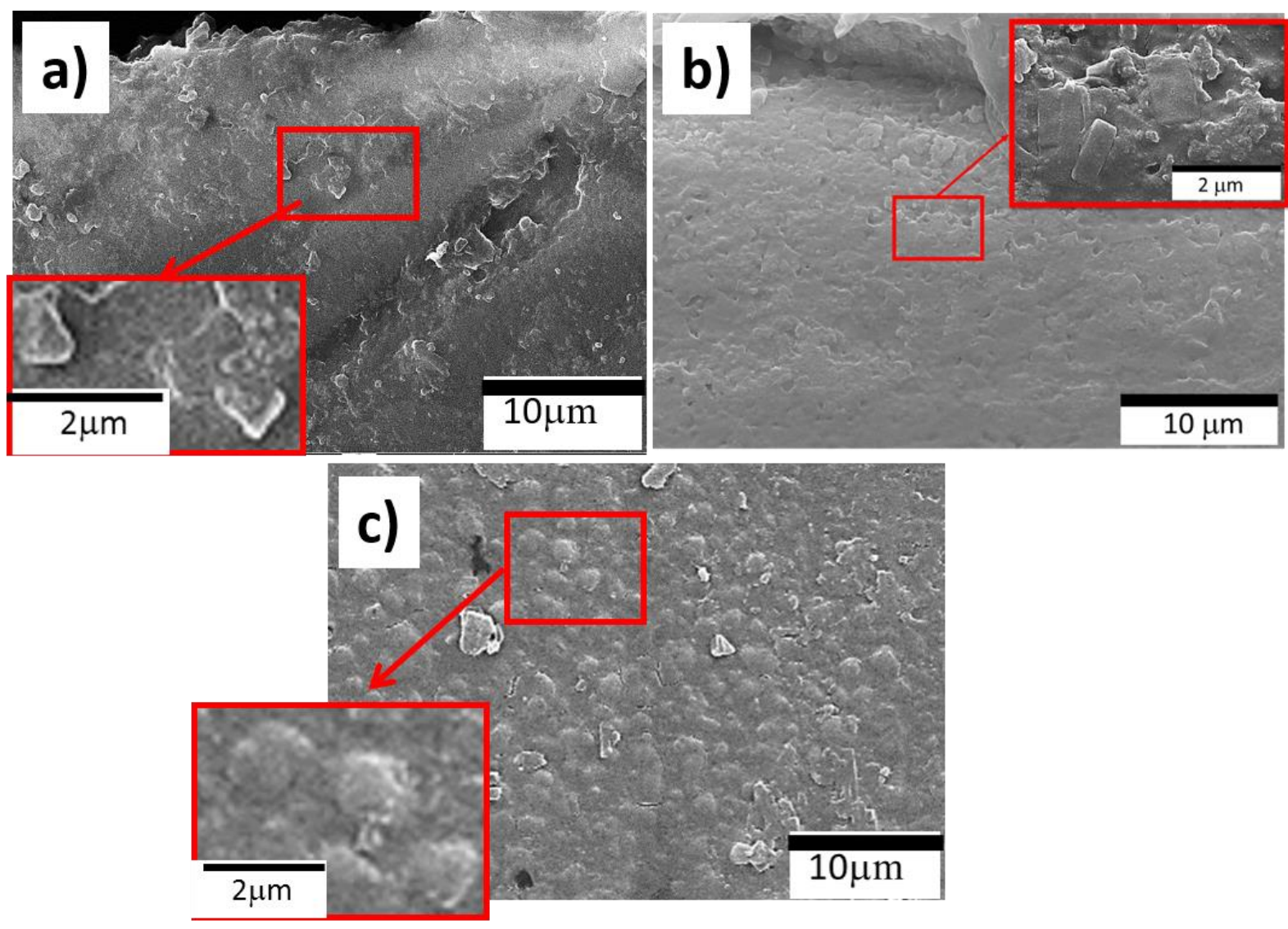

Fig. 4. SEM micrographs of melt spun Al-7075 alloys showing changes in microstructures with addition of $\mathrm{Nb}$ of a) without $\mathrm{Nb}, \mathrm{b}) 0.2$ and c) $0.5 \mathrm{pct}$ 
These kinds of small equiaxed secondary particles are in favor of a structure, generally bring about higher mechanical properties [33]. The occurring of rounded / spherical like secondary phases can be clarified according to the literature as following, because of growth of a seed crystal diffusions controlled, and the radial growth rates of an isolated crystal floating in the metallic melt are essentially isotropic. In addition, solute gradients in the small volume of melt covered by a tiny seed are radial symmetrical, which is also in favor of a rounded outline. In the literature, It has been stated that a higher undercooling level can help these tiny seed crystals, to grow isotropically, resulting in a rounded / globular shape[34]. Moreover, it has been stated that in $\mathrm{Al}$ alloys, an increased concentration of modifier agent in liquid phase lead to an increased constitutional undercooling [35]. On the other hand, in reference [19], it has been stated that $\mathrm{Nb}$ can form a solid solution in $\mathrm{Al}-\mathrm{Si}-\mathrm{Fe}-\mathrm{Nb}$ alloy, as well as diffuse into secondary phases (intermetallics). Hence, in this study we conclude that some $\mathrm{Nb}$ atoms played a role as a modifier agent in the liquid Al matrix and led to an increment in the constitutional undercooling, which resulted in the formation of rounded / globular-like intermetallic phases.

In Figure 5 changes of microhardness values with the contribution of $\mathrm{Nb}$ are given. The variations in the microhardness values of the specimens with the supplement of $\mathrm{Nb}$ agree with the above results, and values and changes of them are given in Figure 5, respectively. Accordingly, while the microhardness value of the base sample (AA00) was $0.31 \mathrm{GPa}$, it was $0.45 \mathrm{GPa}$ for the $0.2 \mathrm{Nb}$ doped sample (AA02), and $0.92 \mathrm{GPa}$ for the $0.5 \mathrm{Nb}$ doped sample (AA05). It means that an increase of approximately 3 times has occurred. It is stated in the literature that modification and refining of the secondary phases in microstructure diminish the probability of crack formation and improve the mechanical properties [36]. Therefore, particle size strengthening caused by the addition of $\mathrm{Nb}$, which brought about refining of coarse secondary phases (Figure 4), can be one possible reason for the increment in the microhardness values. Moreover, as stated above, we concluded that $\mathrm{Nb}$ can be dissolved in the rapidly solidified aluminum matrix by looking at the XRD analysis (Figure 2(d)), which is in accordance with the reference [19].

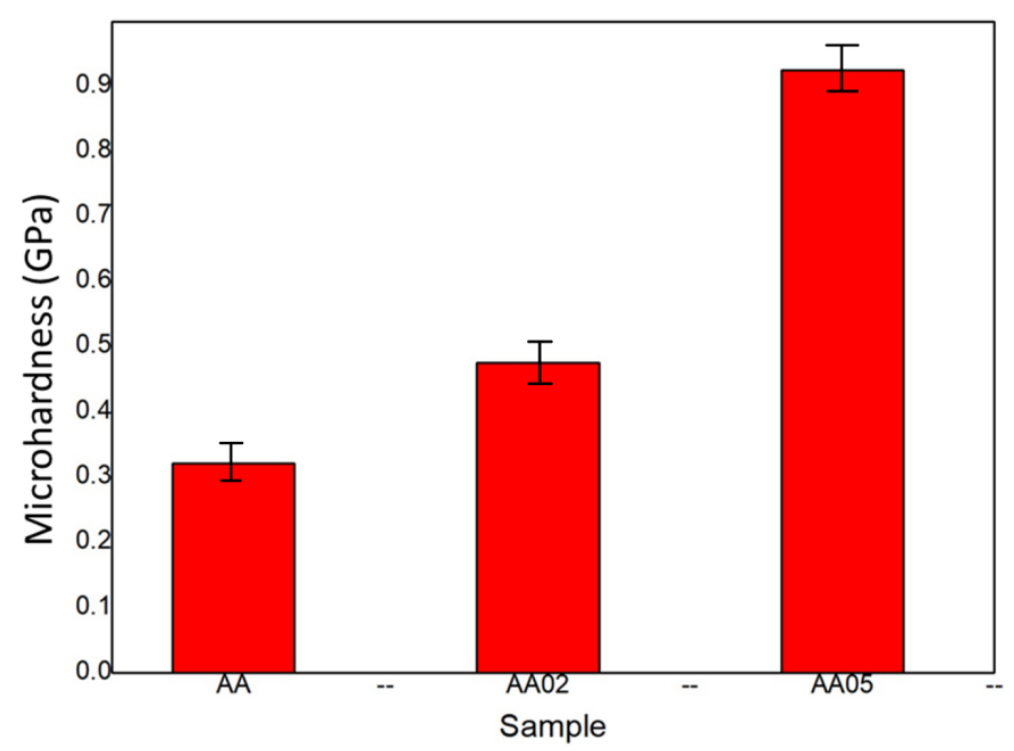

Fig. 5. Changes in the dynamic microhardness values of melt spun Al-7075 alloys with different amount of $\mathrm{Nb}$ addition

Hence, other possible cause for the increment in the microhardness values can be solid solution hardening. In addition, $\mathrm{Nb}$ atoms can cause distortions in the lattice structure by 
acting as the substitutional atom in the structure. Of course, the increase in the density of dislocation also means that this increased the hardness. Lin et al. Stated in their study that the cooling rate was also effective in increasing the density of dislocation. It was determined by Lin et al. that dislocation strengthening had an effect at high cooling rates [2]. The data we obtained in our study supports Lin's approach.

\section{CONCLUSIONS}

In this study, it's reported the effects of the addition of $\mathrm{Nb}$ on the microstructural properties of melt spun Al-7075 alloys. The results can be summarized as follows:

- $\mathrm{Nb}$ addition to Al-7075 alloy gradually caused reduction in particle size of $\alpha$-Al phases. And with the $\mathrm{Nb}$ additive, both the distributions of $\alpha$-Al phases became more homogeneous and their shapes transformed from an irregular structure to a coaxial structure.

- The Nb contribution to the Al-7075 alloy caused the secondary phases in the matrix to decrease in size and to evolve their shape from a sharp-edged particle-like structure to a coaxial rounded / spherical structure.

- $\quad \mathrm{Nb}$ additive made to Al-7075 alloy has caused a significant increase in microhardness values. Approximately 3 times higher microhardness value was obtained in the sample with $0.5 \% \mathrm{Nb}$ by weight.

\section{REFERENCES}

1. S.K. Patel, V.P. Singh, B.S. Roy, B. Kuriachen, Recent research progresses in Al-7075 based insitu surface composite fabrication through friction stir processing: A review, Mater. Sci. Eng. B Solid-State Mater. Adv. Technol. (2020). https://doi.org/10.1016/j.mseb.2020.114708.

2. Y. Lin, S. Mao, Z. Yan, Y. Zhang, L. Wang, Melt spinning induces sub-micrometric/micrometric grained structure and dislocations in $7075 \mathrm{Al}$ alloy, J. Alloys Compd. (2015). https://doi.org/10.1016/j.jallcom.2015.08.146.

3. J.R. Davis, ASM Specialty Handbook: Aluminum and Aluminum Alloys, ASM Int. (1993).

4. J.R. Davis, Light Metals and Alloys-Aluminum and Aluminum Alloys, Alloy. Underst. Basics. (2001).

5. Y. Lin, B. Wu, S. Li, S. Mao, X. Liu, Y. Zhang, L. Wang, The quantitative relationship between microstructure and mechanical property of a melt spun Al-Mg alloy, Mater. Sci. Eng. A. (2015). https://doi.org/10.1016/j.msea.2014.10.047.

6. M. Szymanek, B. Augustyn, D. Kapinos, S. Boczkal, J. Nowak, The production of material with ultrafine grain structure in Al-Zn alloy in the process of rapid solidification, Arch. Foundry Eng. (2014). https://doi.org/10.2478/afe-2014-0037.

7. J. Rakhmonov, G. Timelli, F. Bonollo, Characterization of the solidification path and microstructure of secondary $\mathrm{Al}-7 \mathrm{Si}-3 \mathrm{Cu}-0.3 \mathrm{Mg}$ alloy with $\mathrm{Zr}, \mathrm{V}$ and $\mathrm{Ni}$ additions, Mater. Charact. (2017). https://doi.org/10.1016/j.matchar.2017.03.039.

8. Y. Chen, C.Y. Liu, Z.Y. Ma, H.F. Huang, Y.H. Peng, Y.F. Hou, Effect of Sc addition on the microstructure, mechanical properties, and damping capacity of Al-20Zn alloy, Mater. Charact. (2019). https://doi.org/10.1016/j.matchar.2019.109892. 
9. Y. Yang, J.J. Licavoli, S.A. Hackney, P.G. Sanders, Coarsening behavior of precipitate $\mathrm{Al} 3(\mathrm{Sc}, \mathrm{Zr}$ ) in supersaturated Al-Sc-Zr alloy via melt spinning and extrusion, J. Mater. Sci. (2021). https://doi.org/10.1007/s10853-021-05981-4.

10. J. Luo, H. Luo, S. Li, R. Wang, Y. Ma, Effect of pre-ageing treatment on second nucleating of GPII zones and precipitation kinetics in an ultrafine grained 7075 aluminum alloy, Mater. Des. (2020). https://doi.org/10.1016/j.matdes.2019.108402.

11. M.A. Moazam, M. Honarpisheh, Residual stress formation and distribution due to precipitation hardening and stress relieving of AA7075, Mater. Res. Express. (2019). https://doi.org/10.1088/2053-1591/ab59b6.

12. Y. Wang, X. Wu, L. Cao, X. Tong, Y. Zou, Q. Zhu, S. Tang, H. Song, M. Guo, Effect of Ag on aging precipitation behavior and mechanical properties of aluminum alloy 7075, Mater. Sci. Eng. A. (2021). https://doi.org/10.1016/j.msea.2020.140515.

13. R. Meshkabadi, G. Faraji, A. Javdani, A. Fata, V. Pouyafar, Microstructure and homogeneity of semi-solid 7075 aluminum tubes processed by parallel tubular channel angular pressing, Met. Mater. Int. (2017). https://doi.org/10.1007/s12540-017-6760-3.

14. Y. Zhao, J. Liu, T.D. Topping, E.J. Lavernia, Precipitation and aging phenomena in an ultrafine grained Al-Zn alloy by severe plastic deformation, J. Alloys Compd. (2021). https://doi.org/10.1016/j.jallcom.2020.156931.

15. B. Binesh, M. Aghaie-Khafri, Modelling and optimization of semi-solid processing of $7075 \mathrm{Al}$ alloy, Mater. Res. Express. (2017). https://doi.org/10.1088/2053-1591/aa8272.

16. S.K. Gautam, N. Mandal, H. Roy, A.K. Lohar, S.K. Samanta, G. Sutradhar, Optimization of processing parameters of cooling slope process for semi-solid casting of ADC 12 Al alloy, J. Braz. Soc. Mech. Sci. Eng. (2018). https://doi.org/10.1007/s40430-018-1213-6.

17. J. Liu, P. Zeng, S. Kou, Solidification cracking susceptibility of quaternary aluminium alloys, Sci. Technol. Weld. Join. (2021). https://doi.org/10.1080/13621718.2021.1893007.

18. S. Marola, D. Manfredi, G. Fiore, M.G. Poletti, M. Lombardi, P. Fino, L. Battezzati, A comparison of Selective Laser Melting with bulk rapid solidification of AlSi10Mg alloy, J. Alloys Compd. (2018). https://doi.org/10.1016/j.jallcom.2018.01.309.

19. M.F. Kilicaslan, S.S. Altaib, C.D. Vurdu, Effect of Ni Addition on the Morphology and Microstructure of Both Conventional Cast and Melt-Spun of Al-Si-Fe-Nb (at wt\%) Alloy, Met. Mater. Int. (2019). https://doi.org/10.1007/s12540-019-00300-8.

20. K. Ma, T. Hu, H. Yang, T. Topping, A. Yousefiani, E.J. Lavernia, J.M. Schoenung, Coupling of dislocations and precipitates: Impact on the mechanical behavior of ultrafine grained $\mathrm{Al}-\mathrm{Zn}-\mathrm{Mg}$ alloys, Acta Mater. (2016). https://doi.org/10.1016/j.actamat.2015.09.017.

21. Y. Yang, J.J. Licavoli, P.G. Sanders, Improved strengthening in supersaturated Al-Sc-Zr alloy via melt-spinning and extrusion, J. Alloys Compd. (2020). https://doi.org/10.1016/j.jallcom.2020.154185.

22. Q. Liu, M. Liu, C. Xu, W. Xiao, H. Yamagata, S. Xie, C. Ma, Effects of Sr, Ce and P on the microstructure and mechanical properties of rapidly solidified Al-7Si alloys, Mater. Charact. (2018). https://doi.org/10.1016/j.matchar.2018.04.018.

23. E.J. Lavernia, T.S. Srivatsan, The rapid solidification processing of materials: Science, principles, technology, advances, and applications, J. Mater. Sci. (2010). https://doi.org/10.1007/s10853009-3995-5.

24. H. Jones, A perspective on the developed of rapid solidification and nonequilibrium processing and its future, Mater. Sci. Eng. A. (2001). https://doi.org/10.1016/S0921-5093(00)01552-5. 
25. X. Meng, D. Zhang, W. Zhang, C. Qiu, G. Liang, J. Chen, Microstructure and mechanical properties of a high-Zn aluminum alloy prepared by melt spinning and extrusion, J. Alloys Compd. (2020). https://doi.org/10.1016/j.jallcom.2019.152990.

26. S. Liu, X. Wang, Q. Zu, B. Han, X. Han, C. Cui, Significantly improved particle strengthening of Al-Sc alloy by high Sc composition design and rapid solidification, Mater. Sci. Eng. A. (2021). https://doi.org/10.1016/j.msea.2020.140304.

27. V. Hotea, J. Juhasz, F. Cadar, Grain refinement of $7075 \mathrm{Al}$ alloy microstructures by inoculation with Al-Ti-B master alloy, in: IOP Conf. Ser. Mater. Sci. Eng., 2017. https://doi.org/10.1088/1757-899X/200/1/012029.

28. F. Wang, D. Qiu, Z.L. Liu, J.A. Taylor, M.A. Easton, M.X. Zhang, Crystallographic study of grain refinement of $\mathrm{Al}$ by $\mathrm{Nb}$ addition, J. Appl. Crystallogr. (2014). https://doi.org/10.1107/S1600576714004476.

29. M. Nowak, L. Bolzoni, N. Hari Babu, Grain refinement of Al-Si alloys by Nb-B inoculation. Part I: Concept development and effect on binary alloys, Mater. Des. (2015). https://doi.org/10.1016/j.matdes.2014.08.066.

30. S. V. Emani, J. Benedyk, P. Nash, D. Chen, Double aging and thermomechanical heat treatment of AA7075 aluminum alloy extrusions, J. Mater. Sci. (2009). https://doi.org/10.1007/s10853-0093879-8.

31. P.B. Prakash, K.B. Raju, K. Venkatasubbaiah, N. Manikandan, Microstructure Analysis and Evaluation of Mechanical Propertiesof Al 7075 GNP's Composites, in: Mater. Today Proc., 2018. https://doi.org/10.1016/j.matpr.2018.03.010.

32. C.M. Allen, K.A.Q. O'Reilly, P.V. Evans, B. Cantor, The effect of vanadium and grain refiner additions on the nucleation of secondary phases in 1XXX A1 alloys, Acta Mater. (1999). https://doi.org/10.1016/S1359-6454(99)00250-5.

33. C. Shi, L. Zhang, G. Wu, X. Zhang, A. Chen, J. Tao, Effects of Sc addition on the microstructure and mechanical properties of cast Al-3Li-1.5Cu-0.15Zr alloy, Mater. Sci. Eng. A. (2017). https://doi.org/10.1016/j.msea.2016.10.063.

34. M.F. Kiliçaslan, F. Yilmaz, S. Ergen, S.J. Hong, O. Uzun, Microstructure and microhardness of melt-spun Al-25Si-5Fe-XCo (X $=0,1$, 3, 5) alloys, Mater. Charact. (2013). https://doi.org/10.1016/j.matchar.2012.12.006.

35. Y.C. Lee, A.K. Dahle, D.H. StJohn, J.E.C. Hutt, The effect of grain refinement and silicon content on grain formation in hypoeutectic Al-Si alloys, Mater. Sci. Eng. A. (1999). https://doi.org/10.1016/S0921-5093(98)00884-3.

36. S.-J. Hong, C. Suryanarayana, Mechanical properties and fracture behavior of an ultrafinegrained Al-20 wt pet Si alloy, Metall. Mater. Trans. A. (2005). https://doi.org/10.1007/s11661005-0187-z. 